\title{
PENGARUH LINGKUNGAN KELUARGA BAHAGIA TERHADAP AKHLAK ANAK
}

\author{
Annisa Solihat ${ }^{1}$, Moh Saeful Ulum ${ }^{2}$ \\ IAILM Suryalaya Tasikmalaya ${ }^{1}$, \\ annisasolihatt03@gmail.com¹,
}

\begin{abstract}
Abstrack
This study aims to determine the effect of a Happy Family Environment on the Moral of Children in Madrasah Diniyah Al-Ikhlash, Pakemitan Kidul Village, Ciawi District, Tasikmalaya Regency. The method used in this research is a descriptive method with a quantitative approach, namely research in the form of expressing the current conditions by considering past conditions through processing the numbers obtained in the study. Based on the results of this study, it can be concluded that children's morals can be improved through a Happy Family Environment. It is recommended that every family member, especially parents, to be more able to improve and create a good and happy family environment so that children's morals can be better.
\end{abstract}

Keywords: Happy Family Environment, Children's Morals

\begin{abstract}
Abstrak
Penelitian ini bertujuan untuk mengetahui pengaruh Lingkungan Keluarga Bahagia terhadap Akhlak Anak di Madrasah Diniyah Al-Ikhlash Desa Pakemitan Kidul Kecamatan Ciawi Kabupaten Tasikmalaya. Metode yang digunakan dalam penelitian ini adalah metode deskriptif dengan pendekatan kuantitatif yaitu penelitian yang berupa untuk mengungkapkan kondisi yang terjadi sekarang ini dengan mempertimbangkan keadaan masa yang telah lalu melalui pengolahan angka-angka yang diperoleh dalam penelitian. Berdasarkan hasil penelitian ini, dapat disimpulkan bahwa akhlak anak dapat meningkat melalui Lingkungan Keluarga Bahagia. Disarankan agar setiap anggota keluarga khususnya orang tua untuk lebih bisa meningkatkan dan menciptakan lingkungan keluarga yang baik dan bahagia supaya akhlak anak menjadi semakin baik.
\end{abstract}

Kata Kunci: Lingkungan Keluarga Bahagia, Akhlak Anak. 


\section{A. PENDAhULUAN}

Lingkungan keluarga menjadi tolok ukur keberhasilan anak dalam pendidikan. Oleh karena itu, terutama orang tua yang memikul tanggung jawab terbesar dalam pendidikan anak, sepatutnya mengembangkan potensi dirinya melalui keikutsertaannya dalam acara-acara yang bermanfaat.

Ridjal berpendapat sebagaimana dikutip oleh Darosy Endah Hyoscyomina (2011:145) menunjukkan bahwa setiap orang pasti mendambakan keluarga yang bahagia dan sejahtera. Keluarga yang penuh dengan rasa aman, tenang, riang gembira dan saling menyayangi diantara anggota keluarga.

Kebahagiaan akan muncul dalam rumah tangga jika didasari ketakwaan, hubungan yang dibangun berdasarkan percakapan dan saling memahami, urusan yang dijalankan dengan bermusyawarah antara suami, istri dan anak-anak. Semua anggota keluarga merasa nyaman karena pemecahan masalah dengan mengedepankan perasaan dan akal yang terbuka (A.M.Ismatulloh, $2015: 60$ ).

Menurut Ahmad Tafsir (Hasan Baharun, 2016 : 103), Lingkungan keluarga merupakan pendidikan yang pertama, karena dalam keluarga inilah anak pertama-tama mendapatkan didikan dan bimbingan. Dikatakan yang utama, karena sebagian besar dari kehidupan anak adalah di dalam keluarga. Adapun tujuan pendidikan anak dalam keluarga adalah agar anak itu menjadi shaleh atau agar anak itu kelak tidak menjadi musuh orang tuanya, yang akan mencelakakan orang tuanya. Dalam lingkungan keluarga terletak dasar-dasar pendidikan. tugas utama dari keluarga bagi pendidikan anak adalah sebagai peletak dasar bagi pendidikan akhlak dan pandangan hidup keagamaan. Di lingkungan keluarga inilah tempat meletakkan dasar-dasar kepribadian anak didik pada usia masih muda, karena pada usia ini anak lebih peka terhadap pengaruh dari pendidikannya.

Berdasarkan latar belakang masalah tersebut, maka penulis merumuskan masalah yang akan diangkat dalam penelitian ini adalah sebagai berikut :

a. Bagaimana keadaan lingkungan keluarga bahagia di Madrasah Diniyah Al-Ikhlash Desa Pakemitan Kidul Kecamatan Ciawi Kabupaten Tasikmalaya?

b. Bagaimana akhlak anak di Madrasah Diniyah Al-Ikhlash Desa Pakemitan Kidul Kecamatan Ciawi Kabupaten Tasikmalaya?

c. Bagaimana pengaruh lingkungan keluarga bahagia terhadap akhlak anak di Madrasah Diniyah Al-Ikhlash Desa Pakemitan Kidul Kecamatan Ciawi Kabupaten Tasikmalaya?

\section{Pengertian Lingkungan Keluarga Bahagia}

Dalam lingkungan keluarga, orang tua menentukan pola pembinaan pertama bagi anak. Ajaran Islam menekankan agar setiap manusia dapat memelihara keluarganya dari bahaya siksa api neraka, juga termasuk menjaga anak dan harta agar tidak menjadi fitnah, yaitu dengan mendidik anak sebaik-baiknya (Hasan Basri dan Beni Ahmad Saebani, 2010 : 113). 
Melalui pendidikan terhadap anak khususnya, orang tua akan terhindar dari bahaya fitnah dan terhindar pula dari bahaya siksa api neraka, sebagaimana firman Allah dalam QS. At-Tahrim ayat 6:

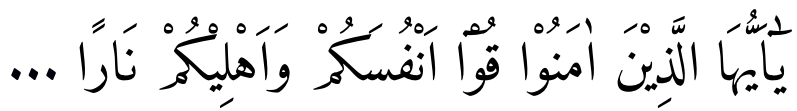

Artinya :

"Wahai orang-orang yang beriman! Periharalah dirimu dan keluargamu dari api neraka." (al-Qur'an dan Terjemah, 2010 : 560)

Anak-anak sejak masa bayi hingga masa sekolah memiliki lingkungan tunggal, yaitu keluarga. Makanya tak mengherankan jika Gilbert Highest menyatakan bahwa kebiasaan yang dimiliki anak-anak sebagian besar terbentuk oleh pendidikan keluarga. Sejak bangun tidur hingga ke saat akan tidur kembali, anakanak menerima pengaruh dan pendidikan dari lingkungan keluarga ( Jalaluddin, $2015: 253$ ).

Lingkungan keluarga diharapkan dapat memberikan kesadaran kepada anakanaknya karena anak adalah titipan Allah sebagai amanah yang wajib dijaga perkembangannya dengan menggunakan strategi dan kiat-kiat yang dapat diterima oleh akal anak. Orang tua tidak memaksakan kehendaknya sendiri kepada anak dan menjaga anak untuk tetap menunaikan shalat fardhu dan berbuat kebajikan.

Menurut Nur Zahidah dan Raihanah (2011:44) menyatakan bahwa keluarga bahagia adalah keluarga yang dapat merasa senang terhadap satu sama lain dan terhadap hidup sendiri serta mempunyai objektif pembinaan keluarga yang jelas dan positif. Bentuk keluarga bahagia dalam Islam menurut Nur Zahidah dan Raihanah (2011 : 41) dibagi ke dalam 3 unsur yaitu : Al-Sakinah, Al-Mawaddah dan AlRahmah.

\section{a. Al-Sakinah}

Al-Sakinah yang membawa maksud ketenangan, ketentraman, kedamaian jiwa yang dipahami dengan suasana damai yang melingkupi rumah tangga dimana suami istri yang menjalankan perintah Allah SWT dengan tekun, saling menghormati dan saling toleransi.

b. Al-Mawaddah

Al-Mawaddah ditafsirkan sebagai perasaan cinta dan kasih sayang antara suami istri yang melahirkan keikhlasan dan saling hormat menghormati antara suami istri dan semua ini akan melahirkan kebahagiaan dalam rumah tangga. Melalui AlMawaddah, pasangan suami istri dan ahli keluarga akan mencerminkan sikap lindung melindungi dan tolong menolong.

c. Ar-Rahmah

Ar-Rahmah dimaksudkan dengan perasaan belas kasihan, toleransi, lemah lembut yang selalunya diikuti oleh ketinggian budi pekerti dan akhlak yang mulia.

\section{Pengertian Akhlak Anak}

Kata akhlak berasal dari bahasa Arab khuluk yang jamaknya akhlaq. Menurut bahasa, akhlak adalah perangai, tabiat, dan agama. Dalam Kamus Besar Bahasa 
Indonesia, kata akhlak diartikan sebagai budi pekerti, watak, tabiat. Berkaitan dengan pengertian khuluq yang berarti agama, Al-Fairuzzabadi berkata, "Ketahuilah, agama pada dasarnya adalah akhlak. Barang siapa memiliki akhlak mulia, kualitas agamanya pun mulia. Agama diletakkan di atas empat landasan akhlak utama, yaitu kesabaran, memelihara diri, keberanian, dan keadilan (Rosihon Anwar, 2010 : 11 ). Akhlak mulia adalah sikap yang santun, sopan, tutur kata lembut penuh kasih sayang, tidak marah, bisa menjadi teladan yang baik, taat beribadah dan berbuat jujur (Mustopa, 2014 : 275).

Menurut Ibnu Miskawaih, akhlak adalah keadaan jiwa seseorang yang mendorongnya untuk melakukan perbuatan-perbuatan tanpa melalui pertimbangan pikiran terlebih dahulu. Sejalan dengan itu, Imam Gazali mengemukakan akhlak adalah suatu sifat yang tertanam dalam jiwa yang daripadanya timbul perbuatanperbuatan dengan mudah tanpa memerlukan pertimbangan pikiran. Dua definisi itu menggambarkan dengan jelas bahwa akhlak secara substansial adalah sifat hati (kondisi hati); bisa baik bisa buruk, yang tercermin dalam prilaku. Jika sifat hatinya baik maka yang muncul adalah akhlak yang baik (al-akhlaq alkarimah). Akan tetapi, jika sifat hatinya busuk maka yang keluar dalam perilakunya adalah akhlak yang buruk (al-akhlaq al-mazmumah). Syahidin (2014: 120 ).

Akhlak yang baik sebenarnya menjadi bagian dari esensi agama dan sekaligus juga buah dari kesungguhan orang-orang yang bertakwa, serta pelatihan bagi orang-orang yang ahli dalam urusan ibadah mendekatkan diri kepada Allah. Sedangkan Akhlak yang buruk lebih sebagai racun pembunuh yang siap membinasakan manusia, menjauhkan manusia dari sisi Allah, serta memasukkan manusia yang memilikinya kepada eratan syaitan (Syamsul Rizal Mz, 2018 : 72).

Akhlak tidaklah semata-mata kelakuan manusia yang nampak atau lahiriah, tetapi banyak aspek yang berkaitan dengan sikap batin ataupun pikiran, seperti akhlak diniyah yang berkaitan dengan berbagai aspek, yaitu pola perilaku kepada Allah, sesama manusia, hingga pola prilaku pada alam (Toto Suryana dkk, 148).

Al-Gazali mengemukakan tanda-tanda manusia berakhlak sebagai berikut.

a. Khusu'dalam salatnya;

b. Berpaling dari hal-hal yang tidak berguna dan tidak ada faidahnya;

c. Selalu kembali kepada Allah SWT;

d. Mengabdi hanya kepada Allah SWT;

e. Selalu memuji dan mengagungkan Allah SWT;

f. Bergetar hatinya jika nama Allah disebut-sebut;

g. Berjalan di muka bumi dengan tawadu dan tidak sombong;

h. Bersikap arif (bijaksana) menghadapi orang-orang awam;

i. Mencintai orang lain seperti ia mencintai dirinya sendiri;

j. Menghormati tamu;

k. Menghargai dan menghormati tetangga;

1. Berbicara selalu baik, santun dan penuh makna;

$\mathrm{m}$. Tidak banyak bicara dan bersikap tenang dalam menghadapi segala persoalan;

n. Tidak menyakiti orang lain dengan ucap, sikap maupun dengan perbuatan. 
Sufi yang lain mengemukakan tanda-tanda manusia berakhlak, antara lain:

a. Memiliki budaya malu dalam interaksi dengan sesamanya;

b. Tidak menyakiti orang lain;

c. Banyak kebaikannya;

d. Benar dan jujur dalam ucapannya;

e. Tidak banyak bicara tetapi banyak kerja;

f. Penyabar dan hatinya selalu bersama Allah SWT;

g. Bersikap tenang dan suka berterimakasih;

h. Rela terhadap segala ketentuan Allah;

i. Bijaksana dan hati-hati dalam bertindak;

j. Disenangi teman dan lawan karena tidak pendendam;

k. Tidak suka mengadu domba;

1. Sedikit makan dan tidur;

m. Tidak pelit dan tidak hasad;

n. Cinta karena Allah dan benci karena Allah SWT.

\section{B. METODE}

\section{Metode Penelitian}

Metode penelitian yang digunakan adalah metode deskriptif dengan penelitian kuantitatif. Metode penelitian ini berusaha untuk menyajikan data dan mengungkapkan fakta-fakta yang sesungguhnya tentang pengaruh lingkungan keluarga terhadap akhlak anak di Madrasah Al-Ikhlash.

\section{Populasi}

Populasi adalah wilayah generalisasi yang terdiri atas : obyek/subyek yang mempunyai kualitas dan karakteristik tertentu yang ditetapkan oleh peneliti untuk dipelajari dan kemudian ditarik kesimpulannya (Sugiyono, 2010 : 117). Populasi pada penelitian ini adalah seluruh anak di Madrasah Diniyah Al-Ikhlas yang berjumlah 29 orang, yang menjadi sampel dalam penelitian ini sebanyak 29 orang.

\begin{tabular}{|c|l|c|}
\hline No & \multicolumn{1}{|c|}{ Kelas } & Jumlah \\
\hline 1 & Kelas 1 MDA & 8 \\
\hline 2 & Kelas 2 MDA & 8 \\
\hline 3 & Kelas 3 MDA & 9 \\
\hline 4 & Kelas 4 MDA & 4 \\
\hline \multicolumn{2}{|c|}{ Jumlah } & 29 \\
\hline
\end{tabular}

\section{Sampel dan Teknik Sampling}

Sampel adalah bagian dari jumlah dan karakteristik yang dimiliki oleh populasi tersebut. Teknik sampling yang digunakan adalah sampling jenuh yaitu 
teknik penentuan sampel bila semua anggota populasi digunakan sebagai sampel. Teknik ini disebut juga dengan sensus atau teknik sampel seadanya (total sampling). Hal ini sering dilakukan jika populasi relatif kecil misalnya kurang dari 30 orang atau penelitian yang ingin membuat generalisasi dengan kesalahan yang sangat kecil (Wawan, $2015:$ 133).

\section{Teknik Pengumpulan Data}
a. Observasi
b. Wawancara
c. Angket (Kuesioner)

\section{Teknik Analisis Data}

Untuk mengetahui data tentang pengaruh lingkungan keluarga terhadap akhlak anak yaitu menggunakan langkah-langkah kerja analisis sebagai berikut :

\section{a. Analisis Variabel}

1) Menghitung rata-rata hitung

$$
=\frac{\sum \mathrm{n} \cdot \mathrm{xi}}{\sum \mathrm{N}}
$$

Keterangan :

${ }^{x}=$ nilai rata-rata $\mathrm{n}=$ banyak data yang sama

$\mathrm{xi}=$ Jumlah skor $\mathrm{x}$ dalam sekumpulan data

$\mathrm{N}=$ Jumlah populasi

2) Menentukan simpangan rata-rata

$$
\mathrm{SR}=\frac{\sum n \cdot[x i-x}{N}
$$

Keterangan : $\mathrm{n}=$ Banyak data yang

sama $\mathrm{xi}=$ data ke ....i

a. $=$ rata-rata hitung

$\mathrm{N}=$ Banyak data tunggal

3) Membuat skala penafsiran dengan banyaknya tingkatan skala mengacu kepada banyaknya option dalam angket.

\section{Sangat baik}

Skor Min + 4 SR

\section{Baik}

Skor Min + 3 SR

$$
\text { Cukup baik }
$$

Skor Min + 2 SR

$$
\text { Rendah }
$$

Skor Min +1 SR

\section{Sangat rendah}

\section{b. Analisis Kolerasi}

1) Menyusun skor data masing-masing variabel $x$ dan $y$.

2) Menyusun urutan data dari yang terkecil hingga terbesar bagi masing-masing variabel (variabel $\mathrm{x}$ dan variabel y). 
3) Memberikan posisi pada setiap data yang telah tersusun.

4) Menentukan rangking pada setiap data dengan imbuhannya. Imbuhan rangking diberikan jika ada data yang sama dengan menggunakan rumus $\sum \frac{1}{n}$ dimana $\mathrm{n}=$ banyaknya data yang sama.

5) Menghitung perbedaan rangking dengan rumus $d=r x-r y$.

$\mathrm{rx}=$ rangking data variabel $\mathrm{x}$

ry = rangking data variabel $\mathrm{y}$

6) Menghitung besarnya koefisien Kolerasi Rank Spearman dari kedua variabel dengan rumus : $\mathrm{rs}=1-6 \sum \mathrm{d}^{2}$

$$
\mathrm{N}^{3}-\mathrm{N}
$$

7) Mengkonfirmasikan koefisien kolerasi rank spearman kepada skala Guilford, yaitu :

$\begin{array}{ll}0,00 & 0,20 \\ 0,21 & 0,40 \\ 0,41 & 0,60 \\ 0,61 & 0,80 \\ 0,81 & 1,00\end{array}$

8) Menghitung Koefisien Determinasi (KP atau KD) dengan rumus : $K D=r s^{2} x$ $100 \%$

9) Menguji hipotesis dengan rumus cara membandingkan $t$ hitung dengan $t$ tabel, dengan kaidah pengujian :

Jika $t$ hitung $\geq t$ tabel maka Ha diterima dan Ho ditolak Jika $t$ hitung $\leq \mathrm{t}$ tabel maka Ha ditolak dan Ho diterima Dengan rumus :

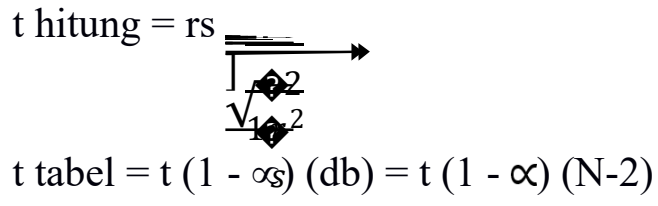

$\mathrm{t}$ tabel $=\mathrm{t}(1-\propto \mathrm{s})(\mathrm{db})=\mathrm{t}(1-\propto)(\mathrm{N}-2)$

\section{HASIL DAN PEMBAHASAN}

\section{Hasil}

Berdasarkan hasil penelitian pengaruh Lingkungan Keluarga terhadap Akhlak Anak di Madrasah Diniyah Al-Ikhlash Desa Pakemitan Kidul Kecamatan Ciawi Kabupaten Tasikmalaya, data yang diolah dan di analisis baik secara parsial maupun kolerasi diperoleh sebagai berikut:

Lingkungan Keluarga Bahagia di Madrasah Diniyah Al-Ikhlash Desa Pakemitan Kidul Kecamatan Ciawi Kabupaten Tasikmalaya tergolong baik. Hal ini terbukti setelah dilakukan penyebaran angket kepada 29 responden dengan jumlah item 15 dan menghasilkan skor terkecil 44 dan skor terbesar 62. Besarnya rata-rata hitung yaitu 55 dan rata-rata hitung tersebut berada pada interval $(53,9$ - 57,2) dengan klasifikasi baik, artinya bahwa salah satu penyebab adanya pengaruh Lingkungan Keluarga Bahagia terhadap Akhlak Anak ada pengaruh yang signifikan. 
Akhlak anak di Madrasah Diniyah Al-Ikhlash Desa Pakemitan Kidul Kecamatan Ciawi Kabupaten Tasikmalaya tergolong cukup baik. Hal ini terbukti setelah dilakukan penyebaran angket kepada 29 responden dengan jumlah item 15 dan menghasilkan skor terkecil 39 dan skor terbesar 61. Besarnya rata-rata hitung adalah 51 berada pada klasifikasi cukup baik dan rata-rata hitung tersebut berada pada interval $(47,4-51,6)$ dengan klasifikasi cukup baik.

Lingkungan Keluarga Bahagia terhadap akhlak anak di Madrasah Diniyah Al-Ikhlash Desa Pakemitan Kidul Kecamatan Ciawi Kabupaten Tasikmalaya tergolong cukup. Hal ini terbukti dengan hasil kolerasi rs $=0,67$. Lingkungan Keluarga Bahagia mempengaruhi akhlak anak sebesar 44\% sedangkan sisanya 56\% dipengaruhi oleh faktor lain. Kolerasi kedua variabel ini yaitu Lingkungan Keluarga Bahagia dan Akhlak Anak

merupakan kolerasi yang signifikan. Hal ini terbukti dengan $t_{\text {hitung }}=4,623>$ $\mathrm{t}_{\text {tabel }}=1,703$. Sehingga Ha diterima dan Ho ditolak. Hal ini berarti bahwa hipotesis yang menyatakan terdapat pengaruh Lingkungan Keluarga Bahagia berpengaruh tinggi terhadap Akhlak Anak sehingga penelitian ini dapat diterima.

\section{Pembahasan}

\section{a. Hasil Analisis Variabel X (Lingkungan Keluarga Bahagia)}

Dari hasil penelitian diatas bahwa Lingkungan Keluarga Bahagia terdapat klasifikasi yang baik. Artinya, bahwa indikator dari Lingkungan Keluarga Bahagia tersebut sudah memenuhi indikator yang terdapat dalam variabel X.

b. Hasil Analisis Variabel Y (Akhlak Anak)

Akhlak anak di Madrasah Diniyah Al-Ikhlash Desa Pakemitan Kidul Kecamatan Ciawi Kabupaten Tasikmalaya pada perhitungan statistik diatas pada klasifikasi cukup baik. Hal ini dapat disimpulkan bahwa Akhlak Anak di Madrasah Diniyah Al-Ikhlash Desa Pakemitan Kidul Kecamatan Ciawi Kabupaten Tasikmalaya cukup baik dan masih memerlukan bimbingan lagi dari keluarga agar meningkatkan Akhlak Anak menjadi lebih baik.

c. Hasil Analisis Kolerasi Variabel X dan Y (Pengaruh Lingkungan Keluarga Bahagia terhadap Akhlak Anak)

Berdasarkan hasil penelitian pengaruh Lingkungan Keluarga terhadap Akhlak Anak di Madrasah Diniyah Al-Ikhlash Desa Pakemitan Kidul Kecamatan Ciawi Kabupaten Tasikmalaya tergolong tinggi. Hal ini terbukti dengan hasil kolerasi $\mathrm{rs}=0,67$. Lingkungan Keluarga Bahagia mempengaruhi akhlak anak sebesar $44 \%$ sedangkan sisanya $56 \%$ dipengaruhi oleh faktor lain. Kolerasi kedua variabel ini yaitu Lingkungan Keluarga Bahagia dan Akhlak Anak merupakan kolerasi yang signifikan. Hal ini terbukti dengan $t_{\text {hitung }}=4,623>t_{\text {tabel }}$ $=1,703$. Sehingga Ha diterima dan Ho ditolak. Hal ini berarti bahwa hipotesis yang menyatakan terdapat pengaruh Lingkungan Keluarga Bahagia berpengaruh tinggi terhadap Akhlak Anak sehingga penelitian ini dapat diterima. 


\section{SIMPULAN}

Berdasarkan hasil penelitian tentang pengaruh Lingkungan Keluarga Bahagia terhadap Akhlak Anak di Madrasah Diniyah Al-Ikhlash Desa Pakemitan Kidul Kecamatan Ciawi Kabupaten Tasikmalaya dapat disimpulkan sebagai berikut:

1. Lingkungan Keluarga Bahagia di Madrasah Diniyah Al-Ikhlash Desa Pakemitan Kidul Kecamatan Ciawi Kabupaten Tasikmalaya baik, hal ini dibuktikan dengan hasil pengolahan data yang telah diperoleh dari penyebaran angket. Nilai rata-rata hitungnya 55 dan simpangan rata-rata nya 3,3 yang berada di klasifikasi baik yaitu ada pada skala penafsiran 53,9 - 57,2 sehingga Lingkungan Keluarga Bahagia di Madrasah Diniyah Al-Ikhlash Desa Pakemitan Kidul Kecamatan Ciawi Kabupaten Tasikmalaya tergolong baik.

2. Akhlak Anak di Madrasah Diniyah Al-Ikhlash Desa Pakemitan Kidul Kecamatan Ciawi Kabupaten Tasikmalaya tergolong cukup baik, hal ini dibuktikan dengan hasil pengolahan data yang diperoleh dari penyebaran angket. Dan nilai rata-rata hitung sebesar 51 dengan simpangan rata-rata sebesar 4,2 berada dalam klasifikasi cukup baik yaitu berda pada skala penafsiran 47,4 - 51,6 sehingga Akhlak Anak di Madrasah Diniyah Al-Ikhlash Desa Pakemitan Kidul Kecamatan Ciawi Kabupaten Tasikmalaya tergolong cukup baik.

3. Dari hasil analisis diperoleh nilai kolerasi antara Lingkungan Keluarga Bahagia dan Akhlak Anak di Madrasah Diniyah Al-Ikhlash Desa Pakemitan Kidul Kecamatan Ciawi Kabupaten Tasikmalaya tergolong tinggi.

Lingkungan Keluarga Bahagia dan Akhlak Anak merupakan kolerasi yang signifikan. Hal ini terbukti dengan $t_{\text {hitung }}=4,623>t_{\text {tabel }}=1,703$. Sehingga Ha diterima dan Ho ditolak. Hal ini berarti bahwa hipotesis yang menyatakan terdapat pengaruh Lingkungan Keluarga Bahagia berpengaruh tinggi terhadap Akhlak Anak sehingga penelitian ini dapat diterima.

\section{Saran}

Setelah mengetahui gambaran empirik Lingkungan Keluarga Bahagia terhadap Akhlak Anak, penulis dapat memberikan saran sebagai berikut:

Dari hasil analisis variabel $\mathrm{X}$ diperoleh keterangan bahwa Lingkungan Keluarga Bahagia terhadap Akhlak Anak dikategorikan baik. Artinya bahwa lingkungan keluarga berpengaruh baik terhadap akhlak anak. Oleh karena itu, orang tua perlu menciptakan lingkungan keluarga yang baik dan bahagia bagi anak.

Dari hasil analisis variabel $\mathrm{Y}$ diperoleh keterangan bahwa Akhlak Anak di Madrasah Diniyah Al-Ikhlash Desa Pakemitan Kidul Kecamatan Ciawi Kabupaten Tasikmalaya dikategorikan cukup baik. Oleh karena itu, selain dari lingkungan keluarga anak juga harus lebih mengenali dirinya perlu memperhatikan lingkungan bermain nya supaya dapat terciptanya akhlak yang baik.

\section{DAFTAR PUSTAKA}

Al-Baqir, Muhammad. (2014). Mengobati Penyakit Hati membentuk Akhlak Mulia. Jakarta : Mizania

Al-Qur'an dan Terjemah. (2010). Bandung : Hilal 
Anwar, Muhammad. (2016). Lingkungan Pendidikan dalam Al-Qur'an (Pengaruhnya dalam Proses Pendidikan). ISTIQRA, Jurnal PenelitianIlmiah, Vol.4, No.2 (Desember)

Anwar, Rosihon. (2010). Akhlak Tasawuf. Bandung : Pustaka Setia

As'ad. (2018). Membangun Keluarga Sakinah. TAZKIYA, Vol.7, No.2 (Januari-Juni)

Atabik, Ahmad. (2013). Konseling Keluarga Islami (Solusi Problematika Kehidupan Berkeluarga). KONSELING RELIGI; Jurnal Bimbingan Konseling Islam, Vol.4, No.1 (Juni)

Baharun, Hasan. (2016). Pendidikan Anak dalam Keluarga; Telaah Epistemologis. Pedagogik; Jurnal Pendidikan, Vol. 3, No. 2, Januari-Juni.

Basri, Hasan dan Beni Ahmad Saebani. (2010). Ilmu Pendidikan Islam (Jilid II). Bandung : Pustaka Setia

Chadijah, Siti. (2018). Karakteristik Keluarga Sakinah dalam Islam. Rausyan Fikr, Vol.14, No.1 (Maret)

Endah Hyoscyomina, Darosy. (2011). Peran Keluarga dalam Membangun Karakter Anak. Jurnal Psikologi Undip, Vol.10, No.2 (Oktober)

Habibah, Syarifah. (2015). Akhlak dan Etika dalam Islam. Jurnal Pesona Dasar, Vol.1, No.4 (Oktober)

HM, Nurmawan dan Abu Fawwaz. (2013). Menggapai Keluarga Sakinah. Jakarta : IKAPI Jalaludin. (2017). Psikologi Agama. Jakarta : Rajagrafindo Persada

Marzuki, Ajat Sudrajat dan Hinu Kesuma. (2009). Prinsip Dasar Akhlak Mulia Pengantar Studi Konsep-konsep Dasar Etika dalam Islam. Yogyakarta : Debut Wahana Press \% FISE UNY

Mursid. (2016). Pengembangan pembelajaran paud. Bandung : Remaja Rosdakarya Mustopa. (2014). Akhlak Mulia dalam Pandangan Masyarakat. Nadwa; Jurnal Pendidikan Islam, Vol.8, No.2 (Oktober)

M. Ismatulloh, A. (2015). Konsep Sakinah, Mawaddah dan Rahmah dalam Al-Qur'an (Perspektif Penafsiran Kitab Al-Qur'an dan Tafsirnya). Mazahih, Vol. XIV, No.1 (Juni)

Mz, Syamsul Rizal. (2018). Akhlak Islami Perspektif Ulama Salaf. Jurnal Pendidikan Islam, Vol.07, No.1 (April)

Rahmi, Amelia. (2013). Pengenalan Literasi Media pada Anak Usia Sekolah Dasar.

SAWWA, Vol.8, No.2 (April)

Sugiyono. (2010). Metode Penelitian Pendidikan (Pendekatan Kuantitatif, Kualitatif, dan $R \& D)$. Bandung : Alfabeta

Suryadarma, Yoke dan Ahmad Hifdzil Haq. (2015). Pendidikan Akhlak Menurut Imam AlGhazali. Vol.10, No.2 (Desember)

Suryana, Toto. dkk. Pendidikan Agama Islam Untuk Perguruan Tinggi. Tiga Mutiara

Syahidin. dkk. (2014). Pendidikan Agama Islam Kontemporer. Ciputat : Indonesia (IKAPI) Tafsir, Ahmad. (2017). Pendidikan Agama dalam Keluarga. Bandung : Remaja Rosdakarya 
Wartono. (2013). Membentuk Lingkungan Pendidikan yang Islami. Edukasi Islami; Jurnal Pendidikan Islam, Vol.02. (Juli)

Watiniyah, Ibnu dan Ummu Ali. (2015). Hadiah Pernikahan Terindah Menuju Sakinah, Mawaddah, wa Rahmah. Jakarta : Kaysa Media

Wawan. Pengantar Statistika Pendidikan. Tasikmalaya : Latifah

Wawan. (2015). Desain Penelitian Kuantitatif. Tasikmalaya : Latifah Press

Zahidah, Nur dan Raihanah. (2011). Model Keluarga Bahagia Menurut Islam. Jurnal Fiqh, No.8, 25-44 